\title{
A Logit Analysis of Farmer Knowledge on Rice Blast Disease Pyricularia grisea [Cook, Sacc] at Mwea Irrigation Scheme, Kirinyaga County, Central Province, Kenya
}

\author{
Kega V.M. ${ }^{1, *}$, Kasina M. ${ }^{2}$, Olubayo F ${ }^{3}$, Kamau G.M ${ }^{4}$, Nderitu, J.H \\ ${ }^{1}$ Kenya Agricultural Research Institute, Kerugoya, Kenya \\ ${ }^{2}$ Kenya Agricultural Research Institute, Crop Health and Biotechnology, National Agricultural Research Laboratories, Kenya \\ ${ }^{3}$ Department of Plant Science and Crop Protection, College of Agriculture and Veterinary Services, University of Nairobi, Kenya \\ ${ }^{4}$ Kenya Agricultural Research Institute, Kenya Agricultural Research Institute Headquarters, Kenya \\ ${ }^{5}$ Out Reach and Resource Mobilization, Mount Kenya University, Kenya
}

Copyright (C) 2015 Horizon Research Publishing All rights reserved.

\begin{abstract}
In Kenya rice is the third most important cereal crop after maize and wheat. However production is constrained by rice blast disease (Pyricularia grisea (Cooke) Sacc). In order to develop viable pest management practices for rice blast disease we need to understand rice farmers' knowledge of the disease. A study was set up to determine the level of farmer knowledge on rice blast disease. A formal questionnaire was administered to a random sample of 119 farmers at Mwea irrigation scheme on 17-22 February 2011. Farmers were requested to provide information about rice, its importance and rice blast disease. Logit regression model was used to identify factors which influence farmer knowledge of rice blast disease. Logit analysis revealed that age had significant influence on rice blast disease knowledge $(p<0.001)$. Rice cultivation as the sole occupation of household head significantly influenced rice blast knowledge $(\mathrm{p}<0.001)$. Rotavating for other farmers $(\mathrm{p}=0.02)$, being a casual labourer $(\mathrm{p}=0.024)$ agricultural training $(\mathrm{p}=0.001)$ and being a man $(\mathrm{p}=0.001)$ had significant influence on rice blast knowledge. The implications of this on dissemination of rice blast disease information are discussed in this paper.
\end{abstract}

Keywords Rice Blast Disease, Logit Analysis, Information, Dissemination

\section{Introduction}

Rice is an important food and cash crop item in East Africa. Of the three East African countries Tanzania has the highest area under rice at 355,000 hectares followed by Uganda at 93,000 hectares. Kenya is the lowest producer with only 13,000 hectares under the crop [5]. In Kenya the small scale farmers are the main producers and acreage range from half an acre to two acres. However there is one large scale grower, Dominion farms in Nyanza province. Over $95 \%$ of production is from the irrigation schemes that include Perkerra in the Rift Valley, West Kano, Ahero and Bunyala in Western Kenya, Mwea in Central highlands, Hola and Bura irrigation schemes in coast province are under rehabilitation. Over $80 \%$ of total production in the country comes from Mwea Irrigation scheme [5].

Rice blast, caused by Ascomycete fungus, Pyricularia grisea (Cooke) Sacc, is a major disease of rice globally. In Kenya, the disease was previously restricted to upland and irrigated rice in Western Province. However, in 2007, the first occurrence of a major outbreak of the disease was recorded at Mwea irrigation scheme in Central Kenya, with estimated yield losses of up to $60 \%$ [7]. There is presently a common consensus that implementation of new crop and pest management (ICPM) programmes should be based on our knowledge of farmer's perception of a pest problem, the pest control decision-making process and the likelihood of the adoption of new technologies and techniques [4].

Logit and probit models are used extensively in social research, probit model for continuous dependent variables taking value between 0 and 1 , and logit model for discrete dependent variables taking binary value of either 0 or 1 [1]. This study was set up to investigate factors that influence farmer's knowledge of rice blast disease at Mwea irrigation scheme.

\section{Methodology}

The study was carried out at Mwea irrigation scheme in Central Province, Kenya. Eight enumerators with no training in agriculture were recruited from Mwea division to collect the data. Individual farmers were interviewed through a semi- structured questionnaire. 
An interview based survey of 119 randomly selected rice farmers was done to collect information about rice, its importance, rice blast disease and its management.

The survey was carried out from 17 to 22 February 2011. Data collected was subjected to descriptive statistics, which included means, standard deviation and frequencies. These were computed by use of SPSS version 16.0 for windows [9]. The statistics described the characteristics of Mwea rice farmers and were also used to answer some of the specific research questions in the study. Logit regression model was used to identify factors which influence farmer knowledge of rice blast disease.

Logistic regression is categorized under Limited Dependent variable model and is extensively used in social research when the dependent variable is dichotomous. The dependent variable takes the value 1 with a probability of success ( $p)$, or the value 0 with probability of failure $(1-p)$. This type of variable is called a Bernoulli (or binary) variable [8]. Here in this study, farmers were grouped as those who had knowledge of rice blast disease and those who had no knowledge of rice blast disease. A value of 1 was given to those who had the knowledge and value 0 was given those who did not the knowledge. Since logistic regression calculates the probability of success (p) over the probability of failure (q), the results of the analysis are in the form of an odds ratio $(\mathrm{p} / \mathrm{q})$.

$$
\text { odds }=\frac{\mathrm{P}}{1-\mathrm{P}}
$$

The independent or predictor variables in logistic regression can take any form. That is, logistic regression makes no assumption about the distribution of the independent variables. They do not have to be normally distributed, linearly related or of equal variance within each group. The relationship between the predictor and response variables is not a linear function in logistic regression; instead, the logistic regression function is used, which is the logit transformation of $P$ :

$$
\log i t[P(x)]=\log \left[\frac{P(x)}{1-P(x)}\right]=\propto+\beta_{1} x_{1}+\beta_{2} x_{2}+. . \beta_{i} x_{i}
$$

where $P(x)$ is probability of having knowledge of rice blast disease, $\alpha$ is the constant of the equation and $\beta$ is the coefficient of the predictor variables(x) or the socio cultural variables in the study, $\beta 0 \ldots \ldots \beta \mathrm{r}$ are the parameters to be estimated or the coefficient of the predictor variables [8]. The analysis provides transformed (antilog) value as exponential logistic coefficient of the respective original coefficient, the "logit" [6].

In this study it was expected that the following socio-demographic characteristics of the respondents would influence the probability of having knowledge of rice blast disease knowledge; 1) age, the older the respondent was, the more likely one would have come across rice blast disease and thus a high chance of having knowledge of the pest, 2) Sex, one particular sex would be involved more closely with rice cultivation and hence would most likely have knowledge of rice blast disease 3) rice farming experience, the more years a farmer was involved in rice cultivation the higher the probability of having come across rice blast disease and thus more likely to have the knowledge of it 4) occupation (rice cultivation as the only occupation) meant that the farmer was in close and constant touch with the crop and thus high chances of having come across rice blast disease and hence a high probability of having knowledge of the disease 5) education, if a farmer had been to school, then there were high chances of having rice blast knowledge 6) training, if a farmer had undergone agricultural training, the more likely he or she would have rice blast disease knowledge 7) access to sources of information, if a farmer had access to sources of information, the more likely that the farmer had come across rice blast knowledge. Therefore, it is possible to deduce the probability of a respondent with known values of these characteristics, having knowledge of rice blast disease.

Unlike multiple regressions where method of least squares is used, logistic transformation being nonlinear in nature uses the maximum likelihood estimate (MLE) method to find the most likely estimates for the coefficients. Instead of minimizing the squared deviations (least squares) MLE maximizes the likelihood that an event will occur. The best fit logit model is based upon the statistics namely likelihood ratio, denoted as $-2 \log$ likelihood ( $-2 \mathrm{LL})$. The minimum value of $-2 \log$ likelihood is 0 , which corresponds to a perfect fit, hence; the lower its value, the better the model. Chi-square test of significance and Nagelkerke $R^{2}$ value provide the basis to represent the overall model fit. Wald statistics provides the statistical significance for each estimated coefficient ( $\beta$ ) [8]. In this study the estimated coefficients $\left(\beta_{0} \beta_{i} \ldots \beta_{n}\right)$ represent the influence of age, sex, rice farming experience, training, access to rice blast disease information, education and occupation on farmer knowledge of rice blast disease.

\section{Results}

The a priori expectation was that seven variables will affect farmer knowledge on rice blast disease in different but specific ways. These variables were age, sex, education, training, non- rice farming income generating occupation in addition to rice cultivation, rice farming experience and sources of information. The variables are explained in (Table $1)$. 
Table 1. Variables identified as determinants of farmer knowledge on rice blast at Mwea irrigation scheme in February 2011

\begin{tabular}{|c|c|}
\hline VARIABLE & EXPLANATION \\
\hline AGE & House Hold Head age in years since birth \\
\hline SEX & Whether male or female \\
\hline \multicolumn{2}{|l|}{ EDUCATION } \\
\hline Education(1) & Never been to school \\
\hline Education(2) & Primary level of education \\
\hline Education(3) & Secondary level of education \\
\hline Education (4) & College level of education \\
\hline TRAINING & Whether the House hold head has ever attended any agricultural training \\
\hline OCCUPATION & Other occupation in addition to rice farming \\
\hline Occupation(1) & Full time rice cultivation and no other occupation \\
\hline Occupation(2) & With salaried employment in addition to rice farming \\
\hline Occupation(3) & Farming Horticultural crops in addition to rice farming \\
\hline Occupation(4) & Farming of field crops like maize and beans in addition to rice farming \\
\hline Occupation(5) & Motor cycle (Boda Boda) taxi operator \\
\hline Occupation(6) & Rotavation in addition to rice farming \\
\hline Occupation(7) & Is a casual labourer in addition to rice cultivation \\
\hline RICE FARMING EXPERIENCE & Number of years of rice cultivation \\
\hline Rice farming experience(1) & Zero years of rice cultivation \\
\hline Rice farming experience(2) & $1-5$ years of rice cultivation \\
\hline Rice farming experience(3) & $6-10$ years of rice cultivation \\
\hline Rice farming experience(4) & $11-15$ years of rice cultivation \\
\hline Rice farming experience(5) & $16-20$ years of rice cultivation \\
\hline Rice farming experience $(6)$ & $21-25$ years of rice cultivation \\
\hline SOURCES OF INFORMATION & Sources of information for agricultural activities \\
\hline Source of information (1) & Farmer to farmer personal contacts \\
\hline Source of information (2) & Radio \\
\hline Source of information (3) & Ministry of Agriculture extension officers \\
\hline Source of information (4) & National irrigation Board(N.I.B) \\
\hline Source of information (5) & Kenya Agricultural Research Institute(KARI) \\
\hline Source of information (6) & Magazines \\
\hline Source of information (7) & AGRO-Input dealer \\
\hline Source of information (8) & Mwea rice growers multipurpose cooperative society(MRGMS) \\
\hline Source of information (9) & Agricultural Field days \\
\hline
\end{tabular}

Table 2. Regression result of Logit regression model for Rice Blast knowledge at Mwea irrigation scheme in February 2011

\begin{tabular}{cccccc}
\hline Variable & B & S.E. & Wald & df & Significance (p value) \\
\hline Education & -1.827 & 1.538 & 1.411 & 1 & $0.235 \mathrm{~ns}$ \\
Training & 4.925 & 1.479 & 11.087 & 1 & $0.001^{* *}$ \\
Age & -.390 & 23771.362 & .000 & 1 & $0.001^{* *}$ \\
Full time rice cultivation & -2.557 & .964 & 7.030 & 1 & $0.001^{* *}$ \\
Rotavation in addition to rice farming & -5.117 & 1.656 & 9.554 & 1 & $0.002^{*}$ \\
Casual labourer in addition to rice farming & -2.237 & .989 & 5.113 & 1 & $0.024^{*}$ \\
farming & 2.458 & .746 & 10.846 & 1 & $0.001^{* *}$ \\
Gender(1) Male & 2.543 & 1.045 & 5.925 & 1 & $0.015^{*}$ \\
No rice farming experience & 1.636 & 0.881 & 3.449 & 1 & $0.063 \mathrm{~ns}$ \\
$1-5$ years rice rice farming experience & 2.528 & 1.071 & 5.570 & 1 & $0.018^{*}$ \\
11-15 years rice farming $\quad$ experience & 2.007 & 2.377 & .000 & 1 & 1.000 \\
\hline Constant &
\end{tabular}

$-2 \log$ likelihood $=276.1$, chi-square $=79.1$, probability $($ chi-square $)=0.00$, Nagerkeke $\mathrm{R} 2=0.30$

Level of significance: ** $(\mathrm{P}<0.001) ; *(\mathrm{P}<0.05)$, ns not significant 


\section{Rice blast disease knowledge}

Logit analysis revealed that age had significant influence on rice blast disease knowledge ( $\mathrm{p}<0.001$ ), rice farming as the sole occupation of household head, hiring out rotavation services to other farmers $(\mathrm{p}=0.02)$, being a casual labourer $(\mathrm{p}=0.024)$, agricultural training $(\mathrm{p}=0.001)$, being a man $(\mathrm{p}=0.001)$ had significant influence on rice blast disease knowledge.

No experience in rice cultivation and rice cultivation experience of one to 15 years had a significant influence on rice blast knowledge possibly implying that farmers had knowledge of rice blast knowledge irrespective of number of years one has been cultivating rice (Table 2).

\section{Discussion}

Results of significance of age on rice blast disease knowledge is possibly due the fact that older farmers were more familiar with rice crop and were able to identify any new diseases. This is also in agreement with studies of Buthelezi et al. [3] who in a study on the influence of scientific and indigenous knowledge, on agricultural land evaluation and soil fertility in South Africa, found that knowledge on these two aspects was easily transmitted between old and young people, despite the disparities in age. Rice farming as the sole occupation of household head, hiring out rotavation services to other farmers, casual labourer and being a man meant that these categories of farmers were in constant contact with the rice crop and therefore able to identify the disease. These findings are supported by Bentley and Thiele [2] who reported that farmers easily identified diseases that were readily easily visible, underpinning the importance of close association with the rice plant with levels of rice blast disease knowledge reported in this study. No experience in rice cultivation and rice cultivation experience of one to 15 years had a significant influence on rice blast knowledge possibly implying that farmers had knowledge of rice blast knowledge irrespective of number of years one has been cultivating rice as this disease was new in the scheme as reported by Muriithi [7]. Being a female was negatively correlated to rice blast knowledge and possible reasons for this were that since disease was relatively new at the time of the study and the main method of disseminating information on the disease was through awareness campaigns and public meetings (Barazas) which are mostly attended by men in the region.

This study suggests that there is need for specific training on the management of rice blast disease and that information dissemination and training efforts should be tailored in such a way as to address the differences in knowledge acquisition and retention between male and female farmers and those with different additional occupation in addition to rice at Mwea irrigation scheme.

\section{Acknowledgements}

The authors are grateful to Director, Kenya Agricultural Research institute (KARI) and the Secretary/ Chief Executive Officer, National Council for Science and Technology (NCST) for funding the study.

\section{REFERENCES}

[1] Adeogun, O.A., A.M. Ajana, O.A. Ayinla, M.T .Yarhere and M.O. Adeogun. 2008. Application of logit models in adoption decisions: A study of hybrid clarias in Lagos State, Nigeria. American-Eurasian J. Agric. and Environ. Science. (4). 468-472.

[2] Bentley, J.W and G.N. Thiele. 1999. Farmer knowledge and management of crop diseases. Agriculture and Human Values. $16: 75-81$

[3] Buthelezi, N., J. Hughes, and A. Modi. 2010. The use of scientific and local knowledge in Agricultural land evaluation and soil fertility studies in two villages in KwaZulu-Natal, South Africa. 19th World congress of soil science and soil solutions for a changing world, 1-6 August 2010, Brisbane Australia proceedings published on DVD.

[4] Dąbrowski, Z. T. and M. Majewski. 2006. Farmers' knowledge, attitude and practices in integrated apple production in central Poland. Folia Horticulturae Ann. 18/1, 2006, 111-125.

[5] GOK. 2009. Ministry of Agriculture. National rice development strategy 2008-2018, 3.1.5 Liberalization of rice irrigation schemes resulting in poor rice management practices, 8 .

[6] Hair, J.F.Jr., W. Black, B. Babin, R. Anderson, and R. Tatham. 2007. Multivariate data analysis. Pearson Education Inc. p 23

[7] Muriithi, C., E. Mugai, A.W. Kihurani, C.J. Nafuma, and S.Amboga. 2010. Determination of silicon from rice by-products and chemical sources on rice blast management. In proceedings of 12th KARI Biennial conference and Research week held at Nairobi, Kenya. 8-12 November 2010, $7-14$.

[8] Padaria, R.N., S. Baldeo, N. Sivaramane, K. N Yaswant., M. Ravi, and S. Surya. 2009. A Logit Analysis of Bt Cotton Adoption and Assessment of Farmers' Training Needs, Indian Research Journal of Extension Education 9 (2): 39-45.

[9] SPSS 2007. Statistical package for social scientists (SPSS) (2007) version 16.0 for windows. 